\title{
Emerging pedagogies for computer-based learning
}

\author{
Niwat Srisawasdi ${ }^{1}$ - Patcharin Panjaburee ${ }^{2}$
}

\section{Introduction}

Over the past decades, the advancement of computers and communication technologies has encouraged an increasing number of computer-based learning systems in contemporary education reform movements. Computer-based learning (CBL) has been referred as the use of computers for instructional purposes, whereas the computer hard- and software as well as the peripherals and input devices are the key components of the educational environment (Ifenthaler 2012). The CBL may involve web-based learning environments (e.g., online adaptive learning environments, online interactive learning environments, intelligent tutoring system, learning management system, and so forth), handheld- or microcomputer-based laboratory, computer simulations or animations, computer or digital games, augmented reality (AR), virtual reality (VR), and mobile or smartphone applications. Currently, it has been argued that CBL environments could provide limited support for the student to gain knowledge. These environments assume the presence of an instructional process to facilitate and scaffold the student in learning. Therefore, teacher and pedagogy are becoming crucial mechanism in CBL environments. For our point of view, the pedagogy for CBL refers to the process

Niwat Srisawasdi

niwsri@kku.ac.th

Patcharin Panjaburee

panjaburee_p@hotmail.com

1 Faculty of Education, Khon Kaen University, 123 Moo 16 Mittraphap Road, Muang, Khon Kaen 40002, Thailand

2 Institute for Innovative Learning, Mahidol University, 999, Phuttamonthon 4 Road, Salaya, Nakorn Pathom 73170, Thailand 
of learning or pedagogical practices with the aid of digitalized content, platforms, facilitators, or environments.

With the widely known knowledge required to effectively teach with CBL, teachers need to know how CBL can enhance the representations of specific content knowledge by making the content easier to learn and strategically promote particular learning processes or pedagogical practices (Koehler et al. 2013; Mishra and Koehler 2006). Importantly, when teaching and learning occur in specific contexts, such contexts impact on complex relationship among knowledge about CBL, content expertise, and pedagogical expertise, and thus the effective use of CBL (Rosenberg and Koehler 2015). In other words, CBL should be applied as a process rather than as a single, isolated, and discrete activity. Therefore, CBL application should be based on sound teaching and learning principles and pedagogies to avoid teaching hardware and software technologies in an isolated manner. Pedagogy and CBL should be considered as natural partners, where pedagogies can encourage active approaches to the process of delivery and assessment of learning. The focus of any CBL should not be on the technology itself, but on how CBL can pedagogically use to improve students' learning process. To make CBL effectively, the use of innovative or emerging pedagogies such as inquiry-based learning approach, knowledge engineering approach, and collaborative learning approach should be an important research and development issues.

This special issue aims to offer insights into the current and future trends and research directions in the application of emerging pedagogies for CBL environments. Some of the key themes likely to shape this special issue include the following: (1) research and practices of emerging pedagogies in CBL, (2) teaching and learning strategies of the pedagogical integration of CBL, (3) environment for enhancing quality of education in formal and informal contexts, (4) development of innovative $\mathrm{CBL}$ for orchestrating with pedagogies, (5) review and theory for the application of pedagogies in CBL, (6) case studies and exemplars for the application of pedagogies in CBL, (7) evaluation for the use of emerging pedagogies in CBL, and (8) discussion about re-thinking or expanding models of teaching and learning in response to the $\mathrm{CBL}$.

\section{The papers in this special issue}

Six papers encompassing three empirical studies and three review articles are included. Among empirical papers, the pedagogical practices that support CBL environments are proposed. Addressing in the first paper by Srisawasdi and Panjaburee, An integrated learning styles and scientific investigation-based personalized web approach: a result on conceptual learning achievements and perceptions of high school students, learning style theory incorporated with inquirybased learning approach based on constructivist learning theory was applied to prepare learning activities for individual students in a web-based learning system. Using an experimental research design, this paper revealed that the students with low physics learning performance when using the integrated learning styles and scientific investigation-based web leaning outperformed those with low physics 
learning performance when using conventional web-based learning. Moreover, the students with low physics learning performance perceived usefulness of the integrated learning styles and scientific investigation-based web leaning more than those with high physics learning performance.

The second paper by Quan, Introducing "mobile DDL (data-driven learning)" for vocabulary learning: an experiment for academic English, employed datadriven learning (DDL) approach which features concordancing through a large number of text collection, can facilitate direct and intensive exposure to authentic language in use for English vocabulary learning with mobile device. Through passive data capture, questionnaire, and interview, the results provided evidence of user-friendly tool in which the mobile DDL approach could enable and deliver contextual and repetitive experience of vocabulary learning through two related features such as context extension and random searching. Furthermore, consistency in the results of applying the mobile DDL approach in learning English learning vocabulary for general or other specific purposes indicated that the approach was helpful and effectiveness in promoting English vocabulary learning.

The third paper by Jarrell et al., The link between achievement emotions, appraisals and task performance: pedagogical considerations for emotions in $C B L E s$, used the control-value theory as the guiding theoretical framework of computer-based learning named XX to help medical students effectively diagnose a patient through a diagnostic simulation. The medical students applied what they have learned in medical school to authentic diagnostic problems. The experiment was conducted to examine the emotions students experienced during authentic problem solving in the XX. Evidence revealed that the students in the positive emotion cluster (1) had the highest subjective control and value appraisals and (2) had the highest perceived performance; however, they had lower levels of actual performance when compared to those who assigned to the low emotion cluster and had actual performance levels comparable to those in the negative emotion cluster. The results suggested that CBLEs could support students by promoting low emotionality rather than intense positive emotionality, while learners engage in a performance-oriented achievement task.

As mentioned previously, CBL has been increasingly used in contemporary education. Among three review articles, a more general perspective on the instructional process to drive CBL in education was provided. Addressing in the fourth paper by Storme et al., The emerging pedagogy of MOOCs, the educational design of technology and practices of study, reviewed research and practices display an overview of MOOCs phenomena from 2008 until today, such as (1) in 2008-2012, cMOOCs, in which the "c" stands for connectivism, are aimed at learning content; (2) in 2012-2014, xMOOCs, in which the "x" stands for extension, are derived from names like TedX or MITx to designate the offering of programs that are not part of the core offering; and (3) in 2014-today, abcMOOCs, which are a multiplication of both form and content, give more attention to instructional design and more interest for higher education. These phenomena were identified such as (1) a scholastic approach, which concentrates on the joint operation of practices and technology, toward MOOCs and (2) concentration on 
educational design of technology and on the development of practices of study that are necessary to deal with technology.

The fifth paper by Alkhaldi et al., A review of contemporary virtual and remote laboratory implementations: observations and findings, systemically reviewed the articles on the contemporary virtual and remote laboratory implementations from research databases, such as IEEE Xplore, ACM Digital Library, and ScienceDirect since 2005 using the following keywords: "virtual lab," "remote lab," "cloud lab," "simulation lab," "online lab." Finally, a total of 11 articles out of 884 were identified as the review targets, such as (1) virtual and remote laboratories brought in new opportunities and possibilities to learning in many different disciplines because of accessibility and flexibility, (2) students had a safer environment to conduct experiments without wasting resources while using the remote and virtual labs, and (3) integrating physical labs with virtual and remote labs in innovative ways using a sound pedagogical framework to support learning could create rich learning environments and ability to achieve higher learning outcomes.

The sixth paper by $\mathrm{Wu}$ and Wang, Research trends in technology-enhanced knowledge building pedagogies: a review of selected empirical research from 2006 to 2015, systematically reviewed the empirical studies on the technology-enhanced knowledge-building pedagogies from 2006 to 2015. Using the Social Science Citation Index (SSCI) database as the literature resources, a total of 55 empirical studies were finally identified as the review targets. These empirical studies were analyzed based on three dimensions for a coding scheme, such as (1) the pedagogy dimension: knowledge-building pedagogies were mostly used rather than integrating knowledge-building pedagogies with domain-specific instructional strategies, (2) the technology dimension: "Knowledge Forum ${ }^{\circledR}$ " platform was mostly used rather than Wiki and general discussion forums, and (3) the methodology dimension: both qualitative and quantitative research methods were mostly used and the duration of knowledge-building learning activities in one semester, importantly, there was merely studies focused on learning process or learning outcomes derived from knowledge building. The future research on technologyenhanced knowledge-building pedagogies was also discussed in this study.

\section{Conclusion}

Pedagogy is an essential part of educational research, but it has been the subject of less attention among educational technology research. Despite the importance of pedagogy in the strategic use of educational technology, pedagogy is frequently missing when researchers describe the implementation of technology in their work. Research has generally taken CBL and pedagogical practices to be separate activities, and research growth in the domains has seen relatively little convergence. We therefore invited the submission of papers for this special issue, which were located at the synergies between CBL and emergent pedagogical practices with the view to highlight some of the uses of CBL that are both innovative and transformative of learning/teaching practice. We hope that, as this special issue six papers, they can be seen as complementary endeavors, each informing and 
improving the others and provide a critical reflection on pedagogic practices for CBL. They provide a rich picture of current efforts to take advantage of these synergies. The development of CBL is still very much a work in progress for both scholars and practitioners, and we look forward to reading more about emergent pedagogical practices for driving CBL in the future issues. Finally, we would like to express our thanks to the authors and referees who have contributed to this Special Issue.

\section{References}

Ifenthaler, D. (2012). Computer-based learning. In N. M. Seel (Ed.), Encyclopedia of the sciences of learning (Vol. 3, pp. 713-716). New York: Springer.

Koehler, M. J., Mishra, P., \& Cain, W. (2013). What is technological pedagogical content knowledge (TPACK)? Journal of Education, 193(3), 13-19.

Mishra, P., \& Koehler, M. (2006). Technological pedagogical content knowledge: A framework for teacher knowledge. Teachers College Record, 108(6), 1017-1054.

Rosenberg, J. M., \& Koehler, M. J. (2015). Context and technological pedagogical content knowledge (TPACK): A systematic review. Journal of Research on Technology in Education, 47(3), 186-210.

Niwat Srisawasdi is currently an Assistant Professor at the Division of Science, Mathematics, and Technology Education in Faculty of Education, Khon Kaen University, Thailand. He is also in charge of Institute of Learning and Teaching Innovation (ILTI) at the university. His research interests include technology-enhanced learning and technological pedagogical content knowledge in STEM fields. His research findings have been published in professional books and journals in science and technology education. He also serves as one of the editorial board members and a reviewer of many international academic journals in science education and technology-enhanced learning.

Patcharin Panjaburee is currently an Assistant Professor of Institute for Innovative Learning, Mahidol University, Thailand. She is interested in computer-assisted testing, adaptive learning, expert systems, and digital material supported learning, inquiry-based mobile learning, and web-based inquiry learning environment. Her research findings have been published in professional journals about technologyenhanced learning, such as Computers \& Education, Educational Technology \& Society, International Journal of Mobile Learning and Organisations, British Journal of Educational Technology, Innovations in Education and Teaching International, and Journal of Computers in Education. She also serves as one of the editorial board members and a reviewer of many international academic journals in educational technology. 